\title{
Internal Allocation of R\&D Funds in Information Industry: the Case of Electronic and Communication Equipment Manufacturing Enterprises
}

\author{
Men Boyang, ${ }^{1, *}$, Lan Hong ${ }^{2}$ \\ ${ }^{1}$ Harbin University of Commerce, Harbin, China \\ ${ }^{2}$ Harbin Institute of Petroleum, Harbin, China
}

\begin{abstract}
The internal optimal allocation of $R \& D$ funds is directly related to the innovation ability of information industry enterprise. Enterprises have different capital source channels at different stages of the life cycle, and the capital investment at different stages should have different focuses. This paper takes a case study of Electronic and communication equipment manufacturing enterprises and considers that the allocation of R\&D funds of information industry enterprise depends on the influence of such factors as technology stock, organizational form and enterprise strategy.
\end{abstract}

\section{Introduction}

The investment of R\&D in information industry which represented by electronic and communication equipment manufacturing is higher than that in ordinary manufacturing enterprise. In the process of enterprise technological innovation, innovation funds is an important investment[1]. Sufficient and stable funds sources is the key to the R\&D and development of electronic and communication equipment manufacturing enterprises. The allocation of R\&D funds is the internal behavior of an enterprise. The research on the allocation of internal resources should analyze the logical starting point of the behavior by combining the different characteristics of each stage of the enterprise life cycle, and then solve the problem of how to realize the effective allocation of $R \& D$ funds and cycle optimization. The analysis paradigm analyzes the driving forces of R\&D funds allocation from two aspects: the source of R\&D funds based on the enterprise life cycle and the investment of R\&D funds based on the product $\mathrm{R} \& \mathrm{D}$ process.

\section{Sources and allocation of R\&D funds for electronic and communication equipment manufacturing enterprises}

\subsection{Lifecycle-based analysis of R\&D funding sources}

Similar to the traditional manufacturing industry, the whole life cycle of electronic and communication equipment manufacturing enterprise includes the embryonic stage, the start-up stage, the growth stage, the maturity stage and the decline stage. The different characteristics of each stage make the source channels of R\&D funds different, and there is similarity with each stage of venture funds[2]. In the recession stage, the $R \& D$ ability of enterprises decreases, the scale of funds investment shrinks, and they gradually withdraw from the market. Therefore, the source of newly introduced funds in the recession stage will not be discussed in this paper.

In the embryonic stage, the main task of the enterprise is to carry out the research and development of new products and new technology, and to upgrade and improve the new products and new technology. At this stage, the technical and market risks are high, the success rate of product and technology research and development is low, and it is difficult to obtain venture funds. Therefore, the R\&D funds of electronic and communication equipment manufacturing enterprises in the embryonic stage mainly come from the enterprise's own funds and the government's policy support funds to the industry. Government R\&D subsidies generally include two ways, namely R\&D direct subsidies and tax incentives (also known as indirect subsidies)[3].

In the initial stage, although the development and trial production of new products or new technologies have been basically completed, the commercial credit of the enterprise is in the initial stage, and there is no net inflow of funds. Therefore, the interest payment pressure of debt financing obtained from banks and other financial institutions is relatively high, and the financial risk is relatively high. Therefore, the $\mathrm{R} \& \mathrm{D}$ funds in the start-up stage mainly come from venture funds with relatively small financing costs, combined with policy support funds, etc.

\footnotetext{
*Corresponding author: merson@163.com
} 
In the growth stage, the core technology of the new product is basically formed, and has a considerable market share. Compared with the previous two stages, the degree of risk faced by enterprises is reduced. The early risk of the enterprise has been released, which has brought good commercial credit for the enterprise. Therefore, the R\&D funds of electronic and communication equipment manufacturing enterprises in the growth stage mainly come from the further investment of venture funds and reasonable loans from banks and other financial institutions. Some excellent enterprises can choose to list on the Growth Enterprise Market to achieve public fund raising. In this stage, the benign development of enterprises generally have medium enterprise scale, in 2012, after China implement the strategy of $R \& D$ to drive the development of electronic and communication equipment manufacturing enterprises R\&D data from 2013 to 2019 as an example(lack of statistics for 2016 due to industry catalog adjustment), the internal investment proportion is very high, and grow faster than the government funding(Fig. 1).

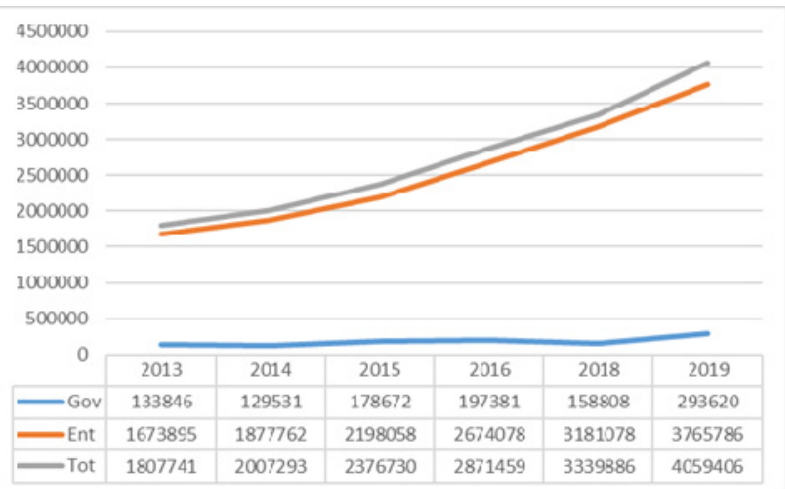

Fig.1.Investment in R\&D funds of medium-size enterprises in China (10000RMB)

In the mature stage, the enterprise's products and related technologies have been stable, the enterprise's production and operation and funds operation have been on the right track, the sales and after-sales services are relatively perfect, the products have a higher market share, and the enterprise has a relatively stable net inflow of funds. Compared with the previous three stages, various risks of the enterprise can be controlled and reduced. Therefore, enterprises in the mature stage of the source of R\&D funds is relatively rich, can be more selective. Enterprises in the mature stage can generally approach or reach the size of large enterprises. Similarly, taking the data of Chinese electronic and communication equipment manufacturing enterprises from 2013 to 2019 as an example (the data of 2016 is missing for the same reason), the growth rate of internal funds investment of enterprises is still higher than that of government investment, and internal funds investment is converging with the total R\&D investment, and government investment accounts for a very small proportion.

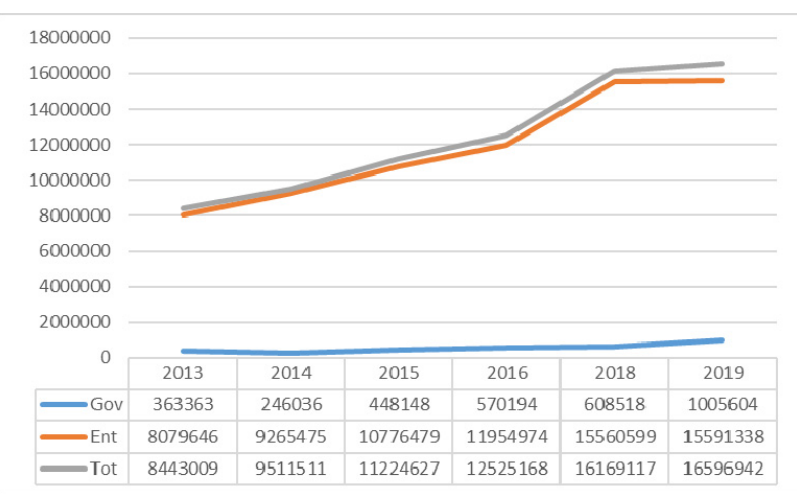

Fig.2. Investment in R\&D funds of large enterprises in China (10000RMB)

\subsection{Analysis of R\&D funds allocation based on R\&D process}

Effectively mastering the characteristics of each $R \& D$ process and the fund allocation situation is very important for the development of the R\&D fund allocation scheme of electronic and communication equipment manufacturing enterprises. The product $R \& D$ process includes a series of innovative activities such as the generation of ideas, research and development, prototype production, manufacturing, sales and marketization. It is the process of transforming knowledge and technology into products accepted and recognized by consumers. It not only includes the development of innovative products, but also includes the commercialization and diffusion of innovative products. In this paper, the product $R \& D$ process is integrated into three stages: research stage, large-scale production stage and product marketization stage.

\subsubsection{Research and development stage}

The funds investment of electronic and communication equipment manufacturing enterprises mainly focuses on the current assets, fixed assets and human funds needed for the research and development of innovative products, specifically involving the acquisition, use and maintenance of innovative talents and other aspects of innovative equipment, materials, patented technology.

\subsubsection{Scale production stage}

It includes the procurement of raw materials, manufacturing and storage of innovative products, which is not only the production process of innovative products, but also the formation process of the cost of innovative products. The funds investment in this stage mainly focuses on the production cost and manufacturing expense.

\subsubsection{Product marketization stage}

Market is the direct target of $R \& D$. Due to the high knowledge-intensive degree of innovative products of electronic and communication equipment manufacturing enterprises, their market recognition degree has greater 
uncertainty, and the degree of marketization of innovative products directly affects the benefits of enterprises. Therefore, the funds investment at this stage is mainly focused on sales expenses.

\section{The motive force of funds allocation of enterprise R\&D}

\subsection{Environmental change and The promotion of Development}

R\&D is the basic means for enterprises to adapt to environmental changes. When the market demand changes or the environmental conditions change, it indicates that the existing products of enterprises can no longer meet the needs of consumers. Enterprises must develop new products to adapt to the new market.The sales revenue of new products not only reflects the R\&D level of enterprises, but also reflects the economic benefits of $\mathrm{R} \& \mathrm{D}[4]$.In this process, the original funds allocation scale, direction, mode and method have been unable to meet the needs of innovative products, so it is necessary to optimize the allocation of R\&D funds to improve the R\&D ability of enterprises, adapt to the changes and development of the environment. Enterprises in the low technology maturity stage are not productive, but their sales are growing rapidly, so they need a lot of funds for $R \& D[5]$.

\subsection{The requirements of sustainable development of enterprises}

In the development process of electronic and communication equipment manufacturing enterprises, the allocation of innovation funds is closely related to the innovative product development and technological transformation of enterprises. It determines the cost and technical level of the product as well as the ability to expand the market, and is the decisive factor that constitutes the competitiveness of an enterprise. Generally, one or two companies will bring an innovative product to market. However, influenced by the herd behavior, other companies, especially those in the same industry, tend to respond positively to it. It will prompt enterprises to improve the efficiency of capital use and save innovation costs by optimizing the allocation of innovation funds. In order to improve the competitiveness in the industry competition, maintain the sustainable development of enterprises.

\section{The conditions of funds allocation for enterprise R\&D}

\subsection{Enterprise funds allocation mechanism}

In order to ensure the effective investment of $R \& D$ institutions and R\&D activities, electronic and communication equipment manufacturing enterprises must set up relevant organizational structures and fund management methods, and the relationship between production and operation funds and R\&D funds can be coordinated through the fund allocation mechanism.If an enterprise invests too much funds in production and operation, once the funds chain of R\&D activities is interrupted, the independent $R \& D$ of the enterprise will have a great negative impact.

\subsection{Quantity of enterprise scientific research}

The scientific research force of R\&D of electronic and communication equipment manufacturing enterprises mainly refers to the cutting-edge technical talents, who are the key to carry out independent R\&D activities of electronic and communication equipment manufacturing enterprises. Under the condition of abundant external R\&D talent resources, how to select, introduce and train special talents, engineers and scientific and technological staff has become an important link in R\&D activities. From the perspective of the allocation of R\&D funds, the investment of cutting-edge technical talents accounts for a large proportion of the total R\&D funds. The lack of research strength will restrict the R\&D of enterprises and increase the cost of R\&D activities.

\subsection{Corporate culture}

The enterprise culture includes the entrepreneur, the enterprise's R\&D consciousness and the enterprise's tolerance to the R\&D failure. Enterprise is the main body of $R \& D$, the entrepreneur is the innovative solutions for, need to investigate the demand of the market and electronic and communication equipment manufacturing enterprises combining its own conditions for configuration design of human resources and funds, enterprise $R \& D$ consciousness refers to the enterprise internal R\&D concept and atmosphere, good R\&D consciousness, is conducive to the external competition into enterprise internal $R \& D$ power. The $R \& D$ of electronic and communication equipment manufacturing enterprises is of high risk. Therefore, the degree of tolerance for R\&D failure also affects the allocation of R\&D funds to a certain extent, which requires enterprises to balance the risk and R\&D benefits.

\section{The function principle of the influencing factors of R\&D funds allocation}

\subsection{Technical factors}

Electronics and communication equipment manufacturing enterprises need to set the type of innovative products or technologies and the expected advanced and maturity of R\&D in advance when making technology selection. In addition, the relationship between product $R \& D$ and technological $R \& D$ should be well coordinated in the R\&D process. Unilateral pursuit of product R\&D will lead to backward technological level of enterprises, lower product quality and higher 
cost. On the contrary, it will make the enterprise's products can not meet the needs of consumers, affecting the market share of the products.

\subsection{Organizational factors}

It is mainly reflected in the enterprise scale, incentive mechanism, organizational structure and human resource management, as well as the coordination ability among various functional departments. All these factors have an important impact on the effective operation of $R \& D$ funds in different $R \& D$ processes.

\subsection{Strategic factors}

The choice of R\&D strategy is an important problem for enterprise $R \& D$, which can be divided into introduced $R \& D$, cooperative $R \& D$ and imitation $R \& D$ strategy. The different R\&D strategies of electronic and communication equipment manufacturing enterprises will lead to the different methods and modes of R\&D funds allocation.

\subsection{R\&D team factors}

The factors of $R \& D$ team include the professional composition, knowledge structure, ability, viewpoint and belief of the personnel involved in R\&D activities. The allocation of R\&D team personnel plays a decisive role in the cost of R\&D human resources, which also affects the cost of R\&D funds allocation in electronic and communication equipment manufacturing enterprises.

\subsection{Individual factors}

It mainly refers to the influence of individual characteristics of entrepreneurs, executives, technology, production and sales personnel on $R \& D$ funds allocation of electronic and communication equipment manufacturing enterprises. Whether the research and development of innovative products, large-scale production or marketization process, are all planned and executed by specific personnel, therefore, the analysis of factors affecting the allocation of $R \& D$ funds should consider individual factors.

\section{Conclusion}

- Information technology enterprises should optimize the structure of capital investment, guide more funds to flow to technology and equipment investment, reduce lowlevel repeated investment and increase the proportion of technology and equipment capital stock with higher technical content, so as to improve the overall technology level.

- Excessive capital accumulation will occupy the resources of original technological innovation and produce crowding out effect. Enterprises should choose reasonable asset supply mode according to technology gap and technology development stage.
- Enterprises should strengthen the impact of technological development stages on investment decisions. An enterprise's correct understanding of its own stage of technological development is conducive to formulating its investment strategy and ensuring its technological progress and productivity improvement..

\section{References}

1. Gong Jiancheng, Chen Kaihua. Measuring R\&D Performance of Chinese High-tech Industries. The Journal of Quantitative \& Technical Economics, vol. 26, pp. 19-33, August 2009.

2. Maryam Haque. National Venture Funds Association 2017 Year Book. https://nvca.org/nvca2017-yearbook-go-resource-venture-ecosystem/, 4th March 2017.

3. Zhao Kai, Wang Hongyuan. The Two-Way Dynamic Coupling and Nonlinear Relationship Between R\&D Subsigy Policy and R\&D Decision. Economic Theory and Business Management, vol. 05, pp. 43-56, May 2018.

4. Hu Ping. Research on Mechanism and Law of Financial Development to High-Tech Industry. Journal of Huanggang Normal University, vol. 02, pp. 16-21, April 2016

5. Liu Tongtong, Wang Lijuan, Wu Fuxiang. Equipment Investment and High Quality Economic Development in Technology Cycle. Commercial Research, vol. 06, pp. 85-95, June 2020 